\title{
Investigation on the use of graphene oxide as novel surfactant to stabilize weakly charged graphene nanoplatelets
}

\author{
Salim Newaz Kazi ${ }^{* *}$, Ahmad Badarudin ${ }^{1}$, Mohd Nashrul Mohd Zubir ${ }^{1}$, Huang Nay Ming ${ }^{2}$, Misni Misran, \\ Emad Sadeghinezhad', Mohammad Mehrali ${ }^{4}$ and Nur Ily Syuhada ${ }^{2}$
}

\begin{abstract}
This paper presents a unique synergistic behavior between a graphene oxide $(\mathrm{GO})$ and graphene nanoplatelet (GnP) composite in an aqueous medium. The results showed that GO stabilized GnP colloid near its isoelectric point and prevented rapid agglomeration and sedimentation. It was considered that a rarely encountered charge-dependent electrostatic interaction between the highly charged GO and weakly charged GnP particles kept GnP suspended at its rapid coagulation and phase separation $\mathrm{pH}$. Sedimentation and transmission electron microscope (TEM) micrograph images revealed the evidence of highly stable colloidal mixtures while zeta potential measurement provided semi-quantitative explanation on the mechanism of stabilization. GnP suspension was confirmed via UV-vis spectral data while contact angle measurement elucidated the close resemblance to an aqueous solution indicating the ability of $\mathrm{GO}$ to mediate the flocculation prone $\mathrm{GnP}$ colloids. About a tenfold increase in viscosity was recorded at a low shear rate in comparison to an individual GO solution due to a strong interaction manifested between participating colloids. An optimum level of mixing ratio between the two constituents was also obtained. These new findings related to an interaction between charge-based graphitic carbon materials would open new avenues for further exploration on the enhancement of both GO and GnP functionalities particularly in mechanical and electrical domains.
\end{abstract}

Keywords: Graphene oxide; Graphene nanoplatelets; Weakly charged colloids; Isoelectric point; Hybrid complexes; Electrostatic stabilization

\section{Background}

Graphene, a single atomic layer of interconnected carbon atoms in honeycomb configuration, and graphene oxide (GO), which earns its name from the oxidation process of graphite, are known to be the most researched materials at present in academia alongside carbon nanotube [1]. The rapidly growing interest of graphene is predominantly attributed to its remarkable properties which have shown to reach the highest theoretical limit known for the material [2-5]. It is evident from the literature that the most versatile method for producing graphene is via chemical exfoliation of graphite to produce $\mathrm{GO}$ followed by subsequent reduction [6-9]. GO is therefore regarded as the most important precursor material to harness the best potentials

\footnotetext{
*Correspondence: salimnewaz@um.edu.my

'Department of Mechanical Engineering, Faculty of Engineering, University of Malaya, Jalan Universiti, 50603 Kuala Lumpur, Malaysia

Full list of author information is available at the end of the article
}

of graphene. The relatively facile nature in material preparation process and high production scalability have propelled extensive research leading to the expansion of its applications in diverse field such as sensors, energy storage devices, photodetectors, and drug delivery [3,10-12].

GO is known to exist in the form several layers of graphene, and its chemical composition is classified into rich oxidized region where hydrophilic functional groups (i.e., epoxy and hydroxyl at the planar surface and carboxyl, carbonyl, ester, ether, diol, ketone, phenol, quinine, and lactones at the edges) are anchored to $\mathrm{sp}^{3}$ carbon atoms as well as pools of un-oxidized graphitic domains which consist of unperturbed hexagonal aromatic chains of $\mathrm{sp}^{2}$ bonded carbon atoms [13-15]. The chemical structure of GO renders the material amphifilic in nature similar to that of surfactant and therefore demonstrate high solubility in aqueous-based solvents $[14,16-18]$. This unique quality 
inherent within the GO structure enables the material to act as an effective stabilizer to isolate hydrophobic materials such as carbon nanotube and water-insoluble drugs [17-27]. The main advantage of having GO as surfactant to stabilize carbon allotropes lies on its chemical compound which mostly contains conjugated carbon to carbon bonding as well as the two-dimensional configuration which serves to improve material functionalities [28]. Further treatment of GO can be performed in presence of other carbon allotropes which would theoretically enhance the overall composites [19,29-31].

It is generally known that the major limitation towards successful application of carbon nanostructures in vast technological domain is associated to its poor dispersion in both aqueous medium and organic solvents [32-34]. Several approaches have been studied for the production of stable aqueous suspension of carbon nanotubes (CNT) as well as other carbon allotropes for instance [35-40]. Chemical functionalization on nanotube and graphene surfaces via the use highly concentrated acid is a widely adopted technique to increase their solubility [41-44]. However, it is also known that modification via chemical route can disrupt the electronic paths in carbon-based materials due to the opening of the conjugated structure leading to the formation of holes on the surface [45]. This would deteriorate the electrical and other quantum effect properties of the nanotubes as well as other carbon-based structures [46]. To address this issue, some researchers have adopted a non-covalent approach by using surfactant as well as charged and noncharged polymers for dispersing carbon nanotubes along with homogenization and ultrasonication [47-50]. This non-destructive functionalization approach is favorable for attaining defect-free carbon nanotube dispersion since the structural integrity remains unaffected with the grafting of the dispersant molecules although the stabilizing effect is limited [47].

Graphene nanoplatelets ( $\mathrm{GnP}$ ) have recently attained immense attention from research community due to its resemblance to idealized graphene in terms of chemical and morphological structure [51-54]. This material is produced from microwave expansion of acid intercalated graphite which yields a planar structure with average thickness of 1 to $10 \mathrm{~nm}$ and varying diameter of 15 to 50 microns [55-57]. The chemical structure of GnP sheets is composed of basal plane layers of aromatic carbon-carbon rings with edges that are prone to oxidation due to the opening of conjugated structure during intercalation and exfoliation processes $[51,57,58]$. The highly intense microwave radiation up to $2.45 \mathrm{GHz}$ in frequency onto the compactly dense graphite flakes results in thermal expansion as high as 500 times its original volume [55]. The expansion yields a wormlike accordion structure which can be further isolated to produce
GnP sheets consisting of few to tens of layers of graphene $[59,60]$.

It was postulated that $\mathrm{GnP}$ would demonstrate quality similar to graphene owing to its much pristine basal plane configuration in comparison to GO [57]. GnP has been shown to bring tremendous improvement in diverse applications due to its extremely high optical, electrical, thermal, and mechanical as well as piezoresistive properties [58,61-65]. The defect on GnP edges which mostly consists of unfilled trigonal carbon bonds promotes favorable site for oxidative reaction with ambient gas to yield more hydrophilic structure which comprises various water-based functional groups (i.e., ethers, carboxyls, or hydroxyls) [51,58]. Thus, it can be said that the solubility of $\mathrm{GnP}$ is size-dependent since more functional groups exist in larger size sheets which contain more structural defects sites [66]. The presence of these functional groups also paves avenues for further covalent and non-covalent functionalization to enhance its solubility [52,67].

It has been proven that the close resemblance of $\mathrm{GnP}$ sheets to graphene mono-structure implies that the former may closely exhibit enhanced thermal and electrical conductivity demonstrated in graphene $[4,65,68,69]$. Due to its unique planar morphology, GnP may offer higher thermal contact area to minimize the thermal resistance especially at low loading levels, enabling much higher thermal conductivity to be attained in comparison to buckeytube carbon-based structures [65,70]. Researchers have used $\mathrm{GnP}$ as a filler material for producing composite structures with promising thermal and mechanical potentials [55,56,71-76]. Further, recently, Do and coworkers [77] have proposed $\mathrm{GnP}$ as a low-cost but effective base material comparable to carbon nanotube and carbon black to further enhance fuel cell catalytic property as well as promote high-level graphitization and resistance to thermal oxidation.

It is evident that the stability of carbon-based materials in an aqueous medium strongly relies on the concentration of hydrophilic functional groups which interact via hydrogen bonding and columbic repulsive force $[14,78]$. The degree of particle stability is commonly interpreted in terms of morphological and quantitative perspectives $[9,13,14]$. For GnP which consists of hydrophilic groups strategically localized at the particle edges, its suspension stability is highly dependent on particle size, and unlike $\mathrm{GO}$, the much pristine basal structure consisting of aromatic carbon rings promotes high tendency for hydrophobic interaction between particles which increases the rate of agglomeration and sedimentation [73,79].

Much effort has been devoted to achieve a stable suspension of graphite nanoplatelets with various surfactants and polyelectrolytes (PEs) [52]. A common quantitative approach for classification of stable colloid is based on 
zeta potential measurement which provides information on the level of electrostatic repulsion between particle surfaces. It is evident from the literature that a zeta potential value of $\pm 35 \mathrm{mV}$ would normally signify a stable colloidal suspension [52,80] and magnitude of higher than $60 \mathrm{mV}$ would indicate excellent stability [80,81]. However, as mentioned above, the unique distribution of oxygen-based functional groups around $\mathrm{GnP}$ peripheral edges may result in misleading interpretation of zeta potential measurement as highlighted by $\mathrm{Lu}$ et al [52]. The actual particle dispersion may take into account the strong hydrophobic interaction at the particle basal plane on top of the electrostatic repulsive nature of its edges. Thus, further modification on the particle solubility is imperative in order to extend its potential as well as harnessing its remarkable properties for diverse applications.

In the present research, GO was used as novel dispersant to stabilize GnP particles in order to improve its processability. It is believed that combination of these elements will ensure all carbon colloidal mixtures without participation of organic surfactants which effectively address the surfactant removal issues. It is postulated that $\pi-\pi$ interaction between the aromatic structure of both constituents may hold the key for ensuring successful stabilization of $\mathrm{GnP}$ as demonstrated by earlier studies on carbon nanotube dispersion using GO $[18,19,21-23,25,31,82,83]$. On top of that, the hydrophilic functional group anchored at the peripheral edge of GnP would theoretically interact with abundant oxidized sites of GO at both the basal plane and the edges to improve the overall stability of GnP colloids.

Further, due to the high stability of GO-based aqueous solution at a wide range of $\mathrm{pH}$ which is evident from the zeta potential value [17], special attention will be directed on exploring its role towards enhancing the stability of $\mathrm{GnP}$ suspension near its point of zero charge (PZC) where particle aggregation and sedimentation dominate. This is based on the previous discoveries on the successful application of highly charged particles to stabilize extremely weak colloidal system via 'haloing effect' $[84,85]$. It is postulated that a virtually similar interaction may manifest for the present colloidal system which consist of a mixture of highly stable GO and pH-sensitive GnP which is known to rapidly flocculate at lower $\mathrm{pH}$ [63]. It is also anticipated that the incorporation of $\mathrm{GnP}$ on $\mathrm{GO}$ via the above interaction will serve to improve the overall performance of the composite structure by specifically targeting the defect site of $\mathrm{GO}$ as platform to complete the interaction. Thus $\mathrm{GnP}$ can also act as colloidal patch to repair defects in GO structure which occur during its synthesis as demonstrated by previous researches $[18,21,29]$.

\section{Methodology}

\section{Material}

The chemicals used for sample preparation are given as follows: Sulfuric acid $\left(\mathrm{H}_{2} \mathrm{SO}_{4}, 98 \%\right)$, phosphoric acid $\left(\mathrm{H}_{3} \mathrm{PO}_{4}, 85 \%\right)$, potassium permanganate $(\mathrm{KMnO} 4,99.9 \%)$, and hydrogen peroxide $\left(\mathrm{H}_{2} \mathrm{O}_{2}, 30 \%\right)$ were obtained from Merck (Darmstadt, Germany). Hydrogen chloride ( $\mathrm{HCl}$, $37 \%)$ and ssodium hydroxide $(\mathrm{NaOH})$ was purchased from Sigma-Aldrich (St. Louis, MO, USA). Expendable graphite flakes (grade 3061) were received from Asbury Graphite Mills Inc (St. Asbury, NJ, USA). Highly purified de-ionized water from Thermo Scientific ${ }^{\text {TM }}$ Barnstead $^{\text {ma }}$ NanoPure $^{\mathrm{TM}}$ system (Thermo Scientific, Waltham, MA, USA) with resistance of $18 \mathrm{M} \Omega . \mathrm{cm}$ was used for the preparation of stock solutions. Graphite nanoplatelet powder (grade C) was purchase from XG Sciences, Inc. (Lansing, MI, USA) with average specific area of $500 \mathrm{~m}^{2} / \mathrm{g}$.

\section{Preparation and characterization techniques}

The GO preparation followed similar procedure as described by Marcano et al. [86] and further simplified by Huang et al [87]. In a typical procedure, $\mathrm{H}_{2} \mathrm{SO}_{4}$ and $\mathrm{H}_{3} \mathrm{PO}_{4}$ with 320: $80 \mathrm{ml}$ ratio along with $3 \mathrm{~g}$ of graphite were mixed in a 2-1 beaker under stirring mode. Eighteen grams of $\mathrm{KMnO}_{4}$ was subsequently poured into the mixture and left for 3 days to allow complete oxidation. At the end of the oxidation process, about $27 \mathrm{ml} \mathrm{H}_{2} \mathrm{O}_{2}$ was added into the solution to terminate the oxidation. The solution was subsequently washed with $1 \mathrm{M} \mathrm{HCL}$ and deionized water (DI) water under centrifugal force up to $11,500 \mathrm{~g}$ using high-speed refrigerated centrifuge unit from HITACHI (model CR21Fiii; Hitachi, Tokyo, Japan) until reaching appropriate $\mathrm{pH}$. The centrifugal process allowed the highly oxidized graphite to dissociate to its individual GO sheets consisting of several atomic layers. About $1 \mathrm{ml}$ of the highly concentrated hydrogel product was finally weighed and dried at $60^{\circ} \mathrm{C}$ for 3 days to determine the actual concentration.

For preparing GO-GnP sample, GnP was first mixed in a $60-\mathrm{ml}$ sampling bottle of DI water solution and underwent sonication for $2 \mathrm{~min}$ at $50 \%$ amplitude using ultrasonic processor (Sonics Vibra-Cell, VCX 750, Sonics \& Materials, Inc., Newtown, CT, USA) with a 13-mm probe. Next, an appropriate amount of GO corresponding to the desired weight percentage was taken from the stock solution and mixed with the GnP solution. Vortex mixer was subsequently used for dispersing the mixture to preserve the $\mathrm{GO}$ size. The $\mathrm{pH}$ was later adjusted using $1 \mathrm{M}$ $\mathrm{HCL}$ and $\mathrm{NaOH}$ to reach the desired value while keeping the solution in stirring mode to promote homogenized chemical reaction. The sample was finally undergone series of testing and characterization processes to further observe, analyze, and verify the hypotheses. 


\section{Sample characterization}

Characterization of the sample was performed using the following analytical devices: The Raman spectral data were reduced via Renishaw inVia Raman microscope system (Renishaw, Gloucestershire, UK) equipped with a 514-nm laser beam. Ultraviolet-visible spectral data were extracted from Varian carry ${ }^{\circledR} 50$ UV-vis spectrophotometer from Agilent Technology (Santa Clara, CA, USA) with dual beam configuration and Xenon flash lamp as light source. The Fourier transform infrared (FT-IR) spectral data were obtained from Perkin-Elmer-FT-IR spectrum 400 (PerkinElmer, Waltham, MA, USA). The crystalline phase was determined using a Phillips X-ray diffractometer (XRD) (Phillips, Amsterdam, Netherlands) employing a scanning rate of $0.033^{\circ} \mathrm{s}^{-1}$ in a $2 \theta$ range from $5^{\circ}$ to $80^{\circ}$ with $\mathrm{Cu} \mathrm{K \alpha}$ radiation $(\lambda=1.5418 \AA)$. The physical structure of the particle was classified using TEM LEO LIBRA-120 (Carl Zeiss, Oberkochen, Germany). Hydrodynamic size and zeta potentials of the particles were measured by Zetasizer Nano ZS (Malvern Instruments Ltd, Malvern, UK) using $4 \mathrm{~mW}$ He-Ne laser operating at a wavelength of $633 \mathrm{~nm}$ with detection angles of $173^{\circ}$ and $13^{\circ}$ for size and zeta potential measurements, respectively. Rheological examination was conducted using Anton Paar Rheometer (model Physica MCR 301, Anton Paar GmbH, Graz, Austria) equipped with double gap concentric tools.

\section{Results and discussions}

\section{Characterization of GO, GnP, and GO-GnP hybrid mixture}

Figure 1a,b,c,d,e,f highlights on the conventional route for identification of GO, GnP, and their hybrid mixture. The colloidal picture provides a fundamental glance on the color and dispersion level of each element in aqueous solution as provided in Figure 1a. The brownish color of GO signifies a successful oxidation process that originates from electronic transition of its molecular orbitals $[9,87,88]$. On the other hand, a much darker solution containing GnP particles manifests which suggests the unperturbed conjugated structure of its basal plane reminiscence to graphite [2,89-91].

The TEM micrograph from Figure 1b clearly shows the morphological structures of GO which consist of a flake-like formation with wrinkles. GnP particle on the other hand appears to be irregular in shape mainly due to the route of its production which involves extreme thermal expansion and high energy sheet isolation processes [55]. Further, some fragments of much smaller GnP particles were seen entrapped on the basal plane which may occur due to size reduction phase involving pulverization process. For GO-GnP hybrid configuration, it was shown that $\mathrm{GnP}$ particles were mostly anchored onto GO sheet which was mostly attributed to the electrostatic and hydrophobic interaction between the particles.
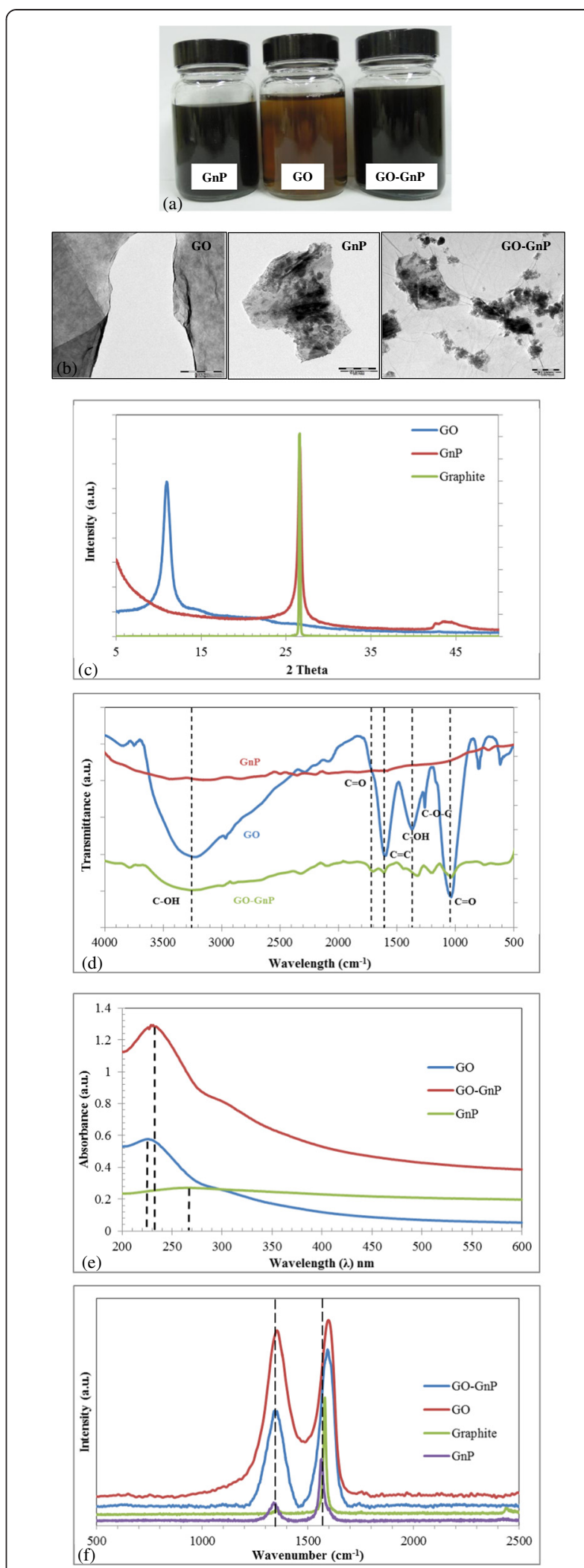

Figure 1 Typical characterization route for GO, GnP, and its hybrid mixture (GO-GnP). (a) Sedimentation image, (b) TEM micrograph, (c) XRD, (d) FT-IR spectra, (e) UV-vis spectra, and (f) Raman spectra. 
As given in Figure 1c, XRD results show different diffraction peaks between $\mathrm{GO}, \mathrm{GnP}$, and graphite (i.e., $10.9^{\circ}$ for $\mathrm{GO}$, and between $26.4^{\circ}$ and $26.5^{\circ}$ for both $\mathrm{GnP}$ and graphite flakes) [92-94]. This is largely due to the change in interlayer spacing for GO to that of graphite and GnP flakes (i.e., $0.87 \mathrm{~nm}$ and $0.34 \mathrm{~nm}$, respectively). The distance between consecutive sheet layers was increased for GO due to the presence of hydrophilic functional groups at the GO basal plane originated from the chemical oxidation.

FT-IR measurements on GO as highlighted in Figure 1d verify the existence of various water-based functional groups formed during the oxidation process as well as the preservation of conjugated aromatic ring at the basal plane $[9,13,95]$. This will render the colloid highly soluble in aqueous-based solution [14]. On the other hand, virtually no significant oxygen-based functional group peak exists to classify $\mathrm{GnP}$ hydrophilic nature suggesting a highly pristine graphitic structure similar to the characteristic of $\mathrm{CNT}[30,43]$. Interestingly, the addition of GnP on GO resulted in the appearance of several prominent peak of hydrophilic-based functional groups on the GnP spectral background indicating the enhancement in the solubility of the GnP colloids.

$\mathrm{UV}$-visible spectral measurement of $\mathrm{GO}$ and $\mathrm{GnP}$ shows that different peaks manifest for each of the constituents as depicted in Figure 1e. The peak at $225 \mathrm{~nm}$ for GO was due to the $\pi \rightarrow \pi^{*}$ transition of the $C=C$ bonding, which is similar to the reported value in the literatures [19]. Meanwhile the shoulder peak around $300 \mathrm{~nm}$ was attributed to $n \rightarrow \pi^{*}$ transition of the carbonyl groups [87]. The much lower maximum peak wavelength of the present GO signifies the increase in oxidation sites with higher distribution of functional groups at the basal plane $[17,87,96]$. For GnP, the peak around $269 \mathrm{~nm}$ was observed which denotes the $\mathrm{C}=\mathrm{C}$ bonding of the aromatic structure along its basal plane. These results mostly concur with carbon-based materials in the literature $[63,96,97]$. The plot for GO-GnP hybrid mixture elucidates the red-shifting of maximum peak wavelength from $225 \mathrm{~nm}$ to $231 \mathrm{~nm}$. This is predominantly due the effect of $\mathrm{GnP}$ anchoring on GO basal structure which was also observed previously in GO-CNT hybrid mixture [26,30]. Further, the addition of GnP into GObased solution increases the intensity of light absorbance which translates into a high level of stability of the system.

Figure 1f shows comparative assessment of Raman spectral measurements between GO, GO-GnP hybrid mixture, and graphite. The results indicate that graphite is distinctively characterized by a prominent G-peak at around $1,580 \mathrm{~cm}^{-1}$ which is a common signature of the first-order scattering of $\mathrm{E} 2 \mathrm{~g}$ phonon from $\mathrm{sp}^{2}$ carbon graphitic lattice $[98,99]$. On the other hand, the Raman spectroscopy measurement for GO unveils a combination of nearly equal composition of $\mathrm{G}$ and $\mathrm{D}$ peaks. The $\mathrm{D}$ peak is commonly interpreted as structural defect on the basal plane as well as signifying the intensity of $\mathrm{sp}^{3}$ carbon molecular structures where the hydrophilic functional groups are appended $[83,100]$. The high intensity of D peak vindicates the previous UV-vis spectral analysis on the decrease in $\pi$-conjugated structure within the GO basal plane [17]. This feature may exhibit intrinsic benefits particularly in further processing of $\mathrm{GO}$ such as functionalization and composite material fabrication and could also potentially act as colloidal stabilizer $[17,19,101]$.

It is also evident that both $\mathrm{D}$ and $\mathrm{G}$ bands of GO-GnP were blue-shifted to a much lower value (i.e., $\mathrm{D}-1,348 \mathrm{~cm}^{-1}$, $\mathrm{E}-1,593 \mathrm{~cm}^{-1}$ ) from GO (i.e., D-1,354 $\mathrm{cm}^{-1}, \mathrm{E}-1,598 \mathrm{~cm}^{-1}$ ) to match the pristine graphitic structure inherent within GnP material (i.e., D-1,340 $\mathrm{cm}^{-1}$, E-1,564 $\mathrm{cm}^{-1}$ ). Further, the peak intensity ratio (i.e., $\mathrm{I}_{\mathrm{D}} / \mathrm{I}_{\mathrm{G}}$ ) value of the hybrid mixture drops almost double from GO which probably suggests that most of the $\mathrm{sp}^{3}$ bonds that connect the carbon atom to the water-based functional groups are overlaid by GnP. This result is almost similar to the study conducted by Cheng et al. [102] on the evolution of peak intensity ratio of repaired GO which shows a decreasing trend signifying the rise of $\mathrm{sp}^{2}$ carbon intensities within the GO sites $[99,103]$. The above ratio is generally understood as representing the degree of crystallization and the alignment of the graphitic planes of the carbon materials [99]. The unique mobilization of $\mathrm{GnP}$ also serves to repair the defect structure within $\mathrm{GO}$ where this $\mathrm{sp}^{3}$ bond mostly manifests. These results strongly suggest the presence of GnP colloid in GO matrix.

\section{Investigation of GO-GnP colloidal stability via imaginary technique}

Figures 2, 3 and 4 show the sedimentation image of the GO stabilized $\mathrm{GnP}$ at two extreme $\mathrm{pH}$, the zeta potential measurement of individual GO and $\mathrm{GnP}$ colloids as well as the TEM micrograph of the morphological architecture of the hybrid colloidal system. These results strengthen the fact that GO can act as efficient stabilizer even at the $\mathrm{pH}$ of flocculation for GnP. This interesting finding warrant further investigation onto the mechanisms involved in the interactions between particle constituents within the colloidal mixture. It is generally known that charged particles are prone to rapid aggregation, flocculation, and sedimentation as the zeta potential reaches the unstable region [96]. This can be illustrated by Figure 3 that shows the rapid increase in $\mathrm{GnP}$ particle hydrodynamic size as the $\mathrm{pH}$ shifts closer to the isoelectric point. However, the addition of GO into this unstable colloidal system exceptionally improves the dispersion level of $\mathrm{GnP}$ which was shown by the sedimentation image. Moreover and quite 


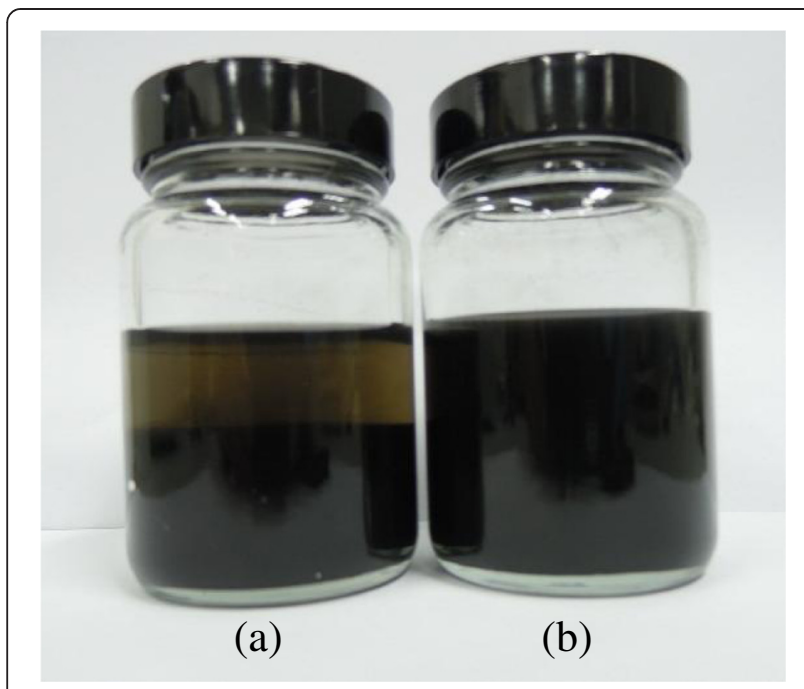

Figure 2 Sedimentation image of GO stabilized GnP. Sedimentation image of $\mathrm{GO}$ stabilized $\mathrm{GnP}$ at (a) $\mathrm{pH}=8$ and (b) $\mathrm{pH}=3.2$ taken after 2 months.

surprisingly, the GnP remained in a stable form even after 2 months.

In contrast, a similar sample prepared at $\mathrm{pH} 8$ which is known to be the stable region for both $\mathrm{GO}$ and $\mathrm{GnP}$ colloids exhibits a sedimentation feature which is evident by the presence of two separate phases. As highlighted in Figure 4, a TEM micrograph shows that GnP remains intact and becomes entrapped on the GO basal plane and between its edges. It is believed that the GnP particles mostly fill up the void that may constitute the defect which is the common morphological character of GO [13]. The size of the GnP is mostly preserved and remains discrete similar to its individual structure. The results strongly suggest that GO can enhance the colloidal stability of GnP which may pave avenues for much facile and scalable processing of carbon-based materials. For instance, a much enhanced lateral and out of plane electrical, thermal, and mechanical properties of GO-GnP thin film composites are expected upon its reduction process which may pave ways for producing highly efficient, compact, and lightweight physical process instruments such as heat exchange and phase change devices [104].

Figures 5 and 6 show the comparison of contact angle measurement between GO-GnP, GO, as well as water to give an insight on the effect of $\mathrm{pH}$ and particle loading onto the wettability of the colloidal system. The results from Figure 5 show that adding GnP and changing the $\mathrm{pH}$ close to its isoelectric point causes a relatively small increase in contact angle measurement in comparison to the corresponding GO and water value. This indicates that GO successfully prevents GnP from experiencing rapid flocculation due to the intensifying attractive van der Waals forces within the colloidal system leading to the expansion of contact angle value. As evident in Figure 6, the results for different $\mathrm{GnP}$ concentration show that the wettability is reduced in accordance to the increase in $\mathrm{GnP}$ concentration which signifies the increase in hydrophobicity of the colloidal system. Nevertheless, these increments are rather small to enable complete alteration of the contact angle to minimize the surface tension. The affinity towards glass plate was still preserved which was mostly attributed to a welldispersed system.

\section{Investigation of GO-GnP colloidal stability via electrophoresis technique}

Figure 7 shows the size and zeta potential measurements of GO at different sonication times and $\mathrm{pH}$. These results explain the reason behind the excellent stability of GO which exhibits high zeta potential value. It was known that zeta potential of more than $60 \mathrm{mV}$ in magnitude indicates high stability of colloidal solution [81].

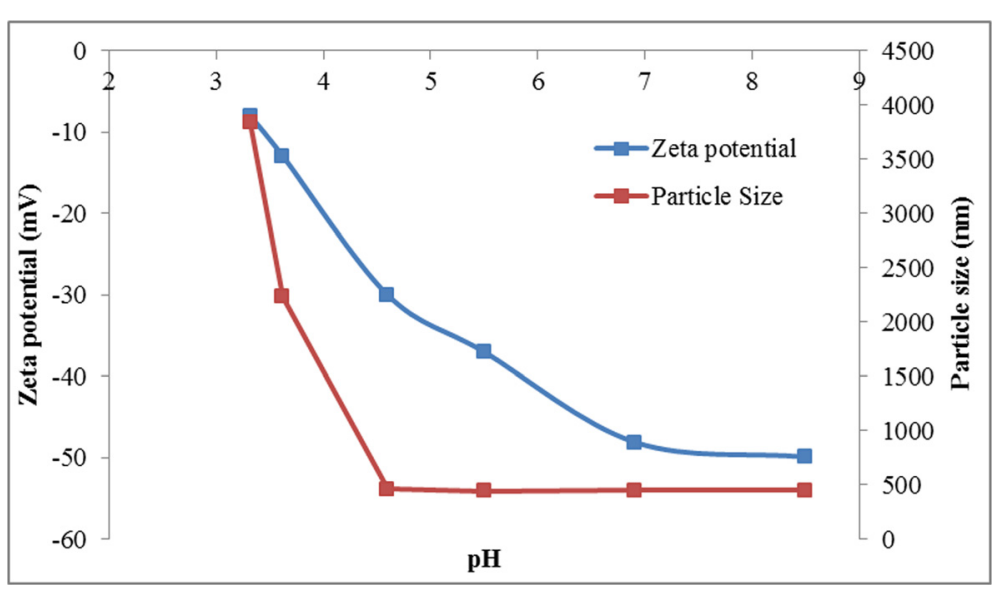

Figure 3 Plots of particle size and zeta potential of GnP with respect to $\mathrm{pH}$. 


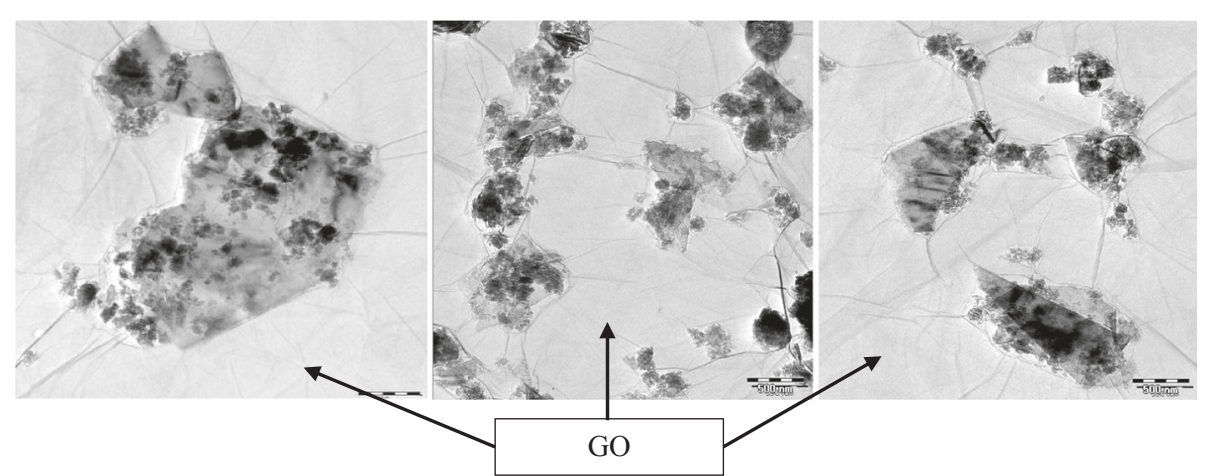

Figure 4 TEM micrograph of GO-GnP hybrid structure at pH 3.2.

This is due to strong repulsive electrostatic forces between adjacent particles originating from high-density electrical charges formed during deprotonation of various functional groups. The figure shows a dramatic drop of zeta potential value after just 2 min of sonication treatment using a probe sonicator. This shows that different sizes of GO particles demonstrate distinctive characteristic of colloidal stability. The as prepared GO contains abundance of oxygen functional groups (hydroxyl, carboxyl, and carbonyl) which render high density of electrical charge per unit area. The collapse of GO structures during sonication process into much smaller fragments may change the charge density surrounding the particles which led to abrupt drops in zeta potential.

Further sonication under similar power intensity may have little effect of the GO overall stability since the particles may have been broken into much smaller

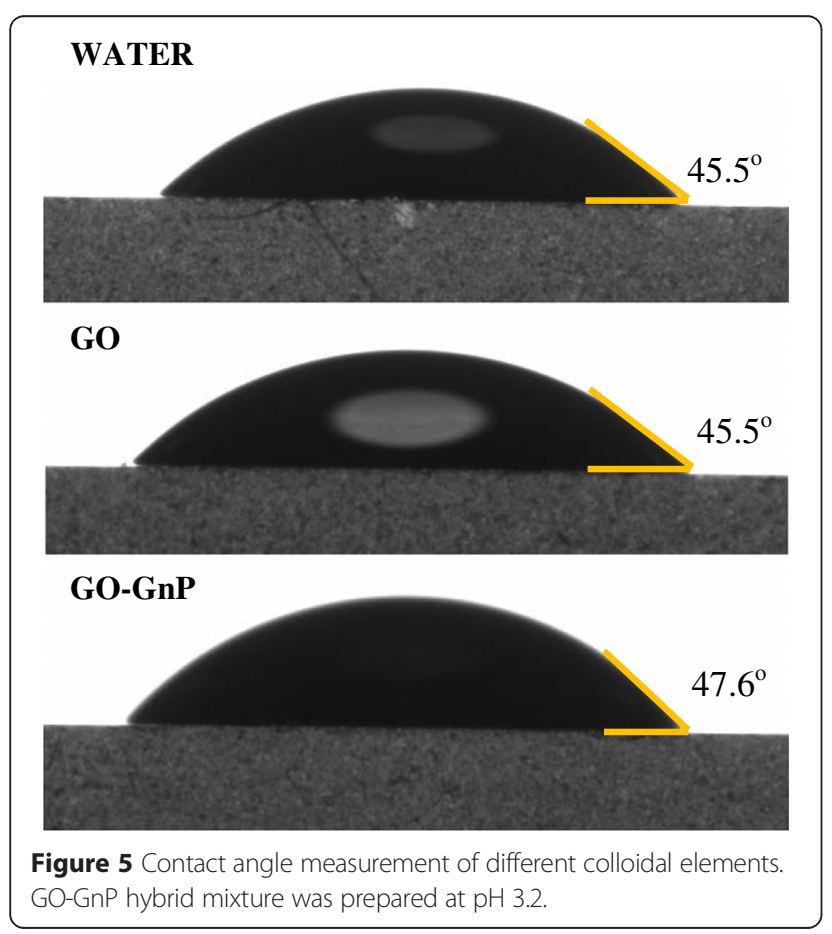

pieces during the initial period of sonication which was evident from the plot of particle size. However, the zeta potential value is still above $50 \mathrm{mV}$ which falls within the high stability region, and the particles was observed to remain suspended for months. Further, Figure 8 shows that the GO colloid produced demonstrates high
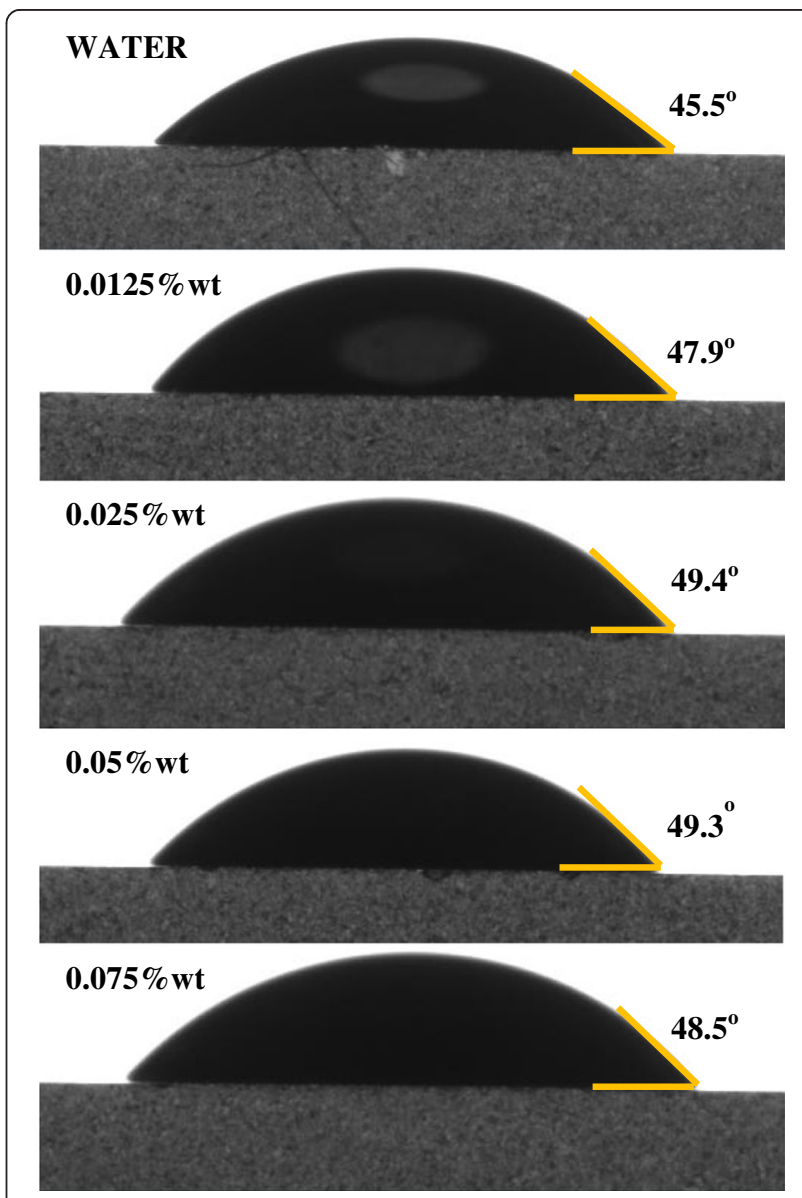

Figure 6 Contact angle measurement of different amounts of GnP elements. Contact angle measurement of different amounts of $\mathrm{GnP}$ elements in GO-GnP colloidal mixture at pH 3.2. GO concentration was fixed at $0.025 \mathrm{wt} \%$. 


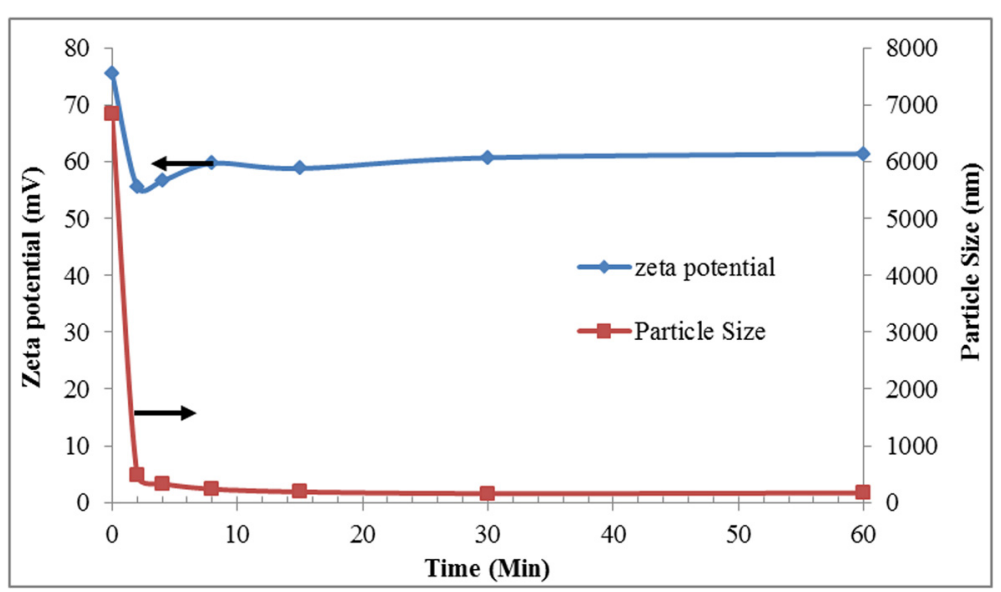

Figure 7 Particle size and zeta potential value of GO with varying sonication time.

robustness against changes in $\mathrm{pH}$. This is also attributed to a large oxidized area within GO produced using the present approach as highlighted by Marcano et al. [86] and was later proven from the peak wavelength absorbance that was blue-shifted to $225 \mathrm{~nm}$ indicating an increase in $\mathrm{sp}^{3}$ domain $[17,87]$.

Figure 9 shows the zeta potential statistical curve for GO-GnP hybrid mixture at two different $\mathrm{pH}$. It is evident that zeta potential measurement of the sample where the $\mathrm{pH}$ was adjusted to $\mathrm{pH} 3.2$ shows much lower deviation in comparison to the sample prepared at $\mathrm{pH} 8$ by which the statistical distribution was broad and relatively poor. Further, the magnitude of zeta potential for the composite mixture at the lower end of $\mathrm{pH}$ is much higher in comparison to individual constituent (i.e., $\mathrm{GO}=-70 \mathrm{mV}$ and $\mathrm{GnP}=-10 \mathrm{mV}$ ). This interesting observation shed light onto the unique interaction between particles within the colloidal matrix. For solution in an extremely basic condition, both $\mathrm{GnP}$ and $\mathrm{GO}$ are in a stable form which is evident by the zeta potential value (i.e., $\mathrm{GO}=60 \mathrm{mV}$ and $\mathrm{GnP}=45 \mathrm{mV}$ ). Thus both particles are mutually repulsive, and since the zeta potential is measured based on the electrophoretic mobility of the particles [105], the sensor translates the frequency shift in the light scattering components into zeta potential value for individual element which results in a much broader distribution. In addition, $\mathrm{GnP}$ is generally known to have much preserved aromatic structure on its basal plane which is hydrophobic in nature. In this context, the colloidal stability is only provided by its parametric edges which is more hydrophilic due to existence of water-based functional groups [51,52]. Therefore, the competing repulsive electrostatic and attractive van der Waals forces between GnP particles and GO sheet result in large fluctuation of measured zeta potential.

On the other hand, at first glance, it was thought that the GnP in GO-based solution would rapidly flocculate and settle down as the $\mathrm{pH}$ was lowered down to 3.2 in

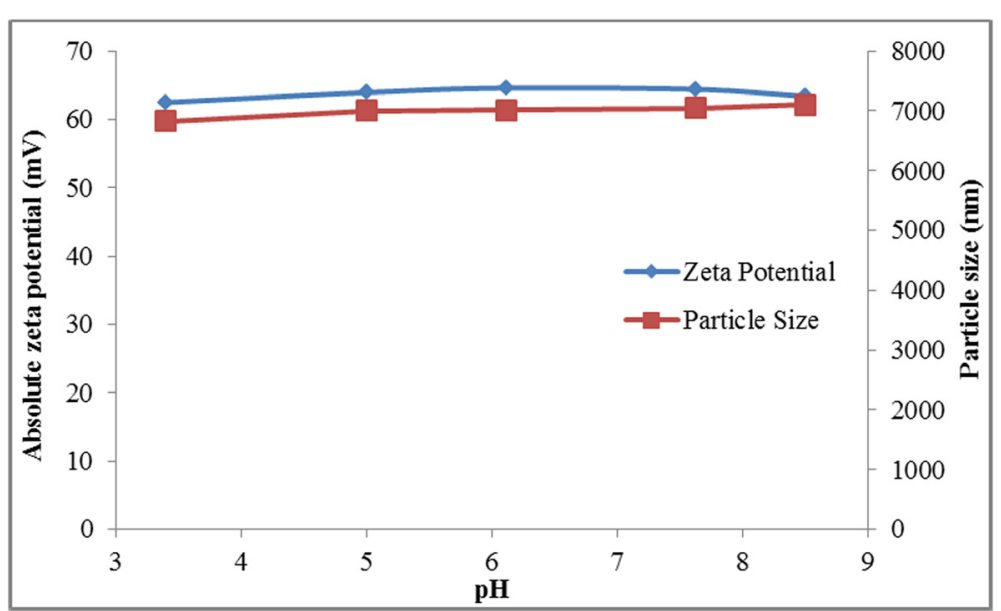

Figure 8 Absolute zeta potential and particle size value of $\mathrm{GO}$ at different $\mathrm{pH}$. 

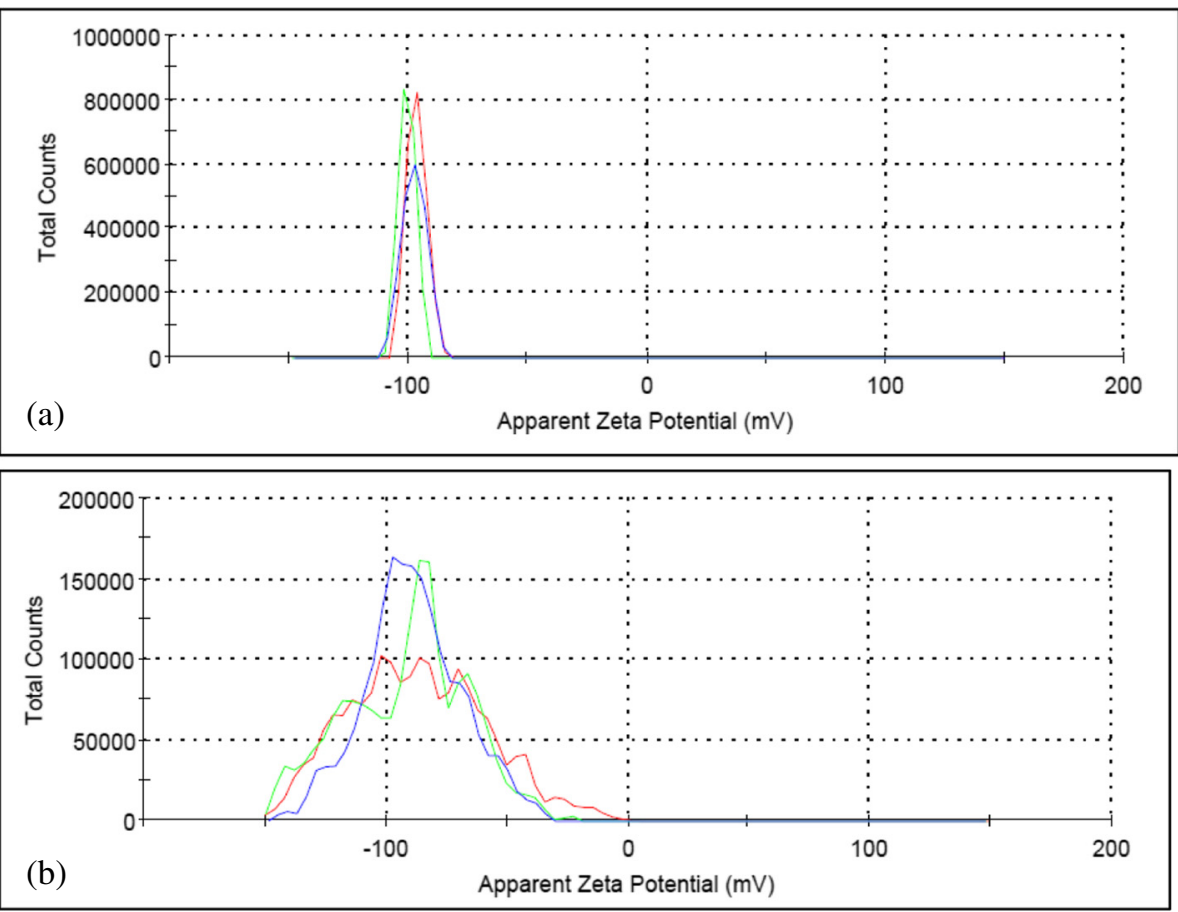

Figure 9 Zeta potential distribution curve for GO-GnP at (a) pH 3.2 and (b) pH 8.

magnitude. However, based on the zeta potential results, it was postulated that the particles strongly interact with GO via columbic force and remaining close to the hydrophilic site of GO without mutual contact. This phenomena is similar to the one discovered by Tohver et al. [85] which shed light on the novel stabilizing mechanism of asymmetrically charged colloidal system. The abnormally high zeta potential value for the hybrid system was also reported previously by Shu Xi et al. [106] and Herman et al. [107] which was probably caused by the small separation distance between the interacting particles, closed to the Dybe length of each constituent. Herman et al. [107] attributed this anomaly to the limitation on the electrophoretic measurement that is highly dependent on particle sphericity.

It is evident that the change in zeta potential value strongly signifies the existence of a unique interaction between the particles. Further, while previous studies focus on understanding the stabilizing effect of low charged microparticles with highly charged nanoparticle [108-112], the present study embarked on the opposite configuration wherein the GnP particles become highly attracted to a much larger GO sheet, but the repulsive nature of both elements prevents their permanent contact within the bimodal system. This result coupled with the imagery evidences may strongly suggest that the hybrid composite mixture exhibits the prevalent characteristic of highly stable colloid which is mutually attractive in a long range but sufficiently repulsive as both particles are drawn closer within the Dybe length zone [113].

Figure 10 shows the zeta potential measurement for series of GO-GnP colloidal mixtures consisting of different amounts of $\mathrm{GnP}$ at specific GO concentration. The results show that the zeta potential value dropped in accordance to the increasing GnP concentration. This is highly expected since the site where GnP particles anchor will become saturated, and additional particles will remain in suspension that causes the overall stability to drop. This loading-sensitive stabilization behavior was also documented previously that outlines the effect of particle concentration and size ratio between high- and lowcharged particles on altering the window of stability of colloidal mixtures $[84,85,112,114]$. However, it is evident from the results that the stability of $\mathrm{GnP}$ in the colloidal system remains high even at four times the concentration of $\mathrm{GO}$ which justifies the underlying importance of GO to enhance the stability of different colloids.

\section{Investigation of GO-GnP colloidal stability via rheological analysis}

Figures 11 and 12 provide a closer look onto the rheological perspective of the hybrid mixture. It was observed that the addition of $\mathrm{GO}$ on the solution containing $\mathrm{GnP}$ colloid causes a significant change in viscosity magnitude at a specific shear rate as evident from Figure 11. The viscosity of the mixture increases more than eight times the 

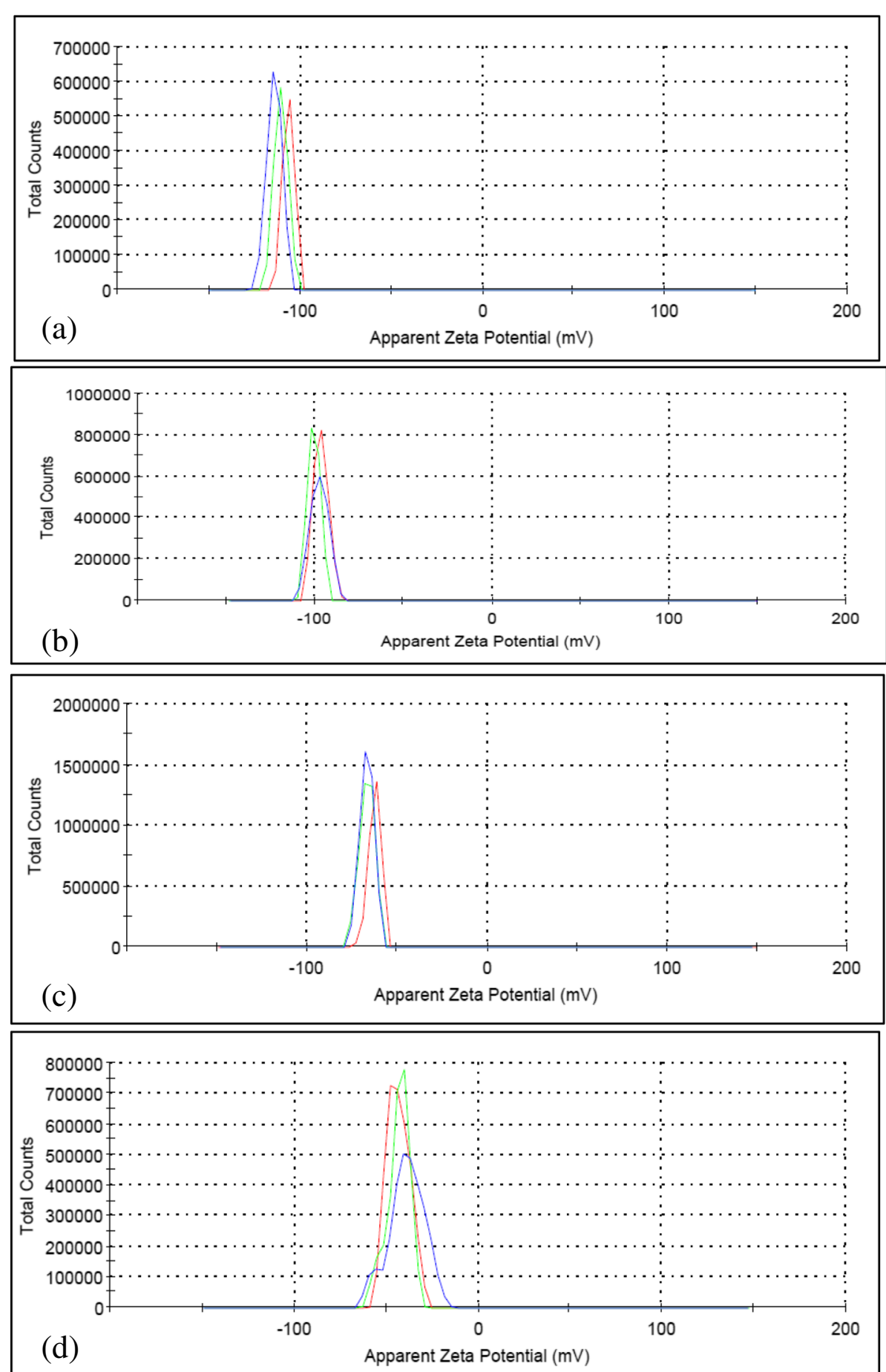

Figure 10 Zeta potential distribution curve for GO-GnP at different GnP concentrations. (a) 0.0125, (b) 0.025, (c) 0.05, and (d) 0.1 wt \%. GO concentration was fixed at $0.025 \mathrm{wt} \%$ and the $\mathrm{pH}$ was kept at 3.2 .

viscosity of GO alone at a shear rate of $1 / \mathrm{s}$. As the shear rate increases, the viscosity drops sharply to match the reference $G O$ value, and at $1 / 200 \mathrm{~s}$ shear rate, the viscosity increment drops to 1.6 times the value of GO. This interesting finding may explain the increase in stability of $\mathrm{GnP}$. The interconnected unstructured network of $\mathrm{GO}$ and
$\mathrm{GnP}$ particles tremendously increases the flow resistance at a low shear rate while the increase in shearing force at higher shear rate causes the highly mobile GnP to hover on the GO sheet. This paves way for rapid realignment of the particle to reduce particle-particle and particle-fluid frictions and facilitate a viscous motion. 


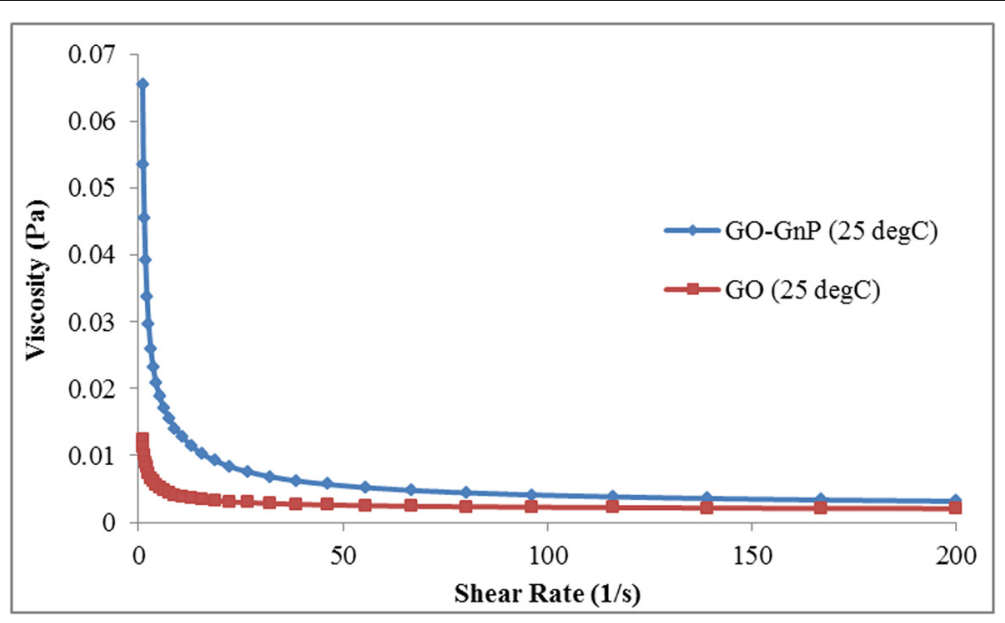

Figure 11 Plot of viscosity against shear rate for GO and GO-GnP hybrid at 1:1 ratio. Both samples were prepared at 0.05 wt $\%$.
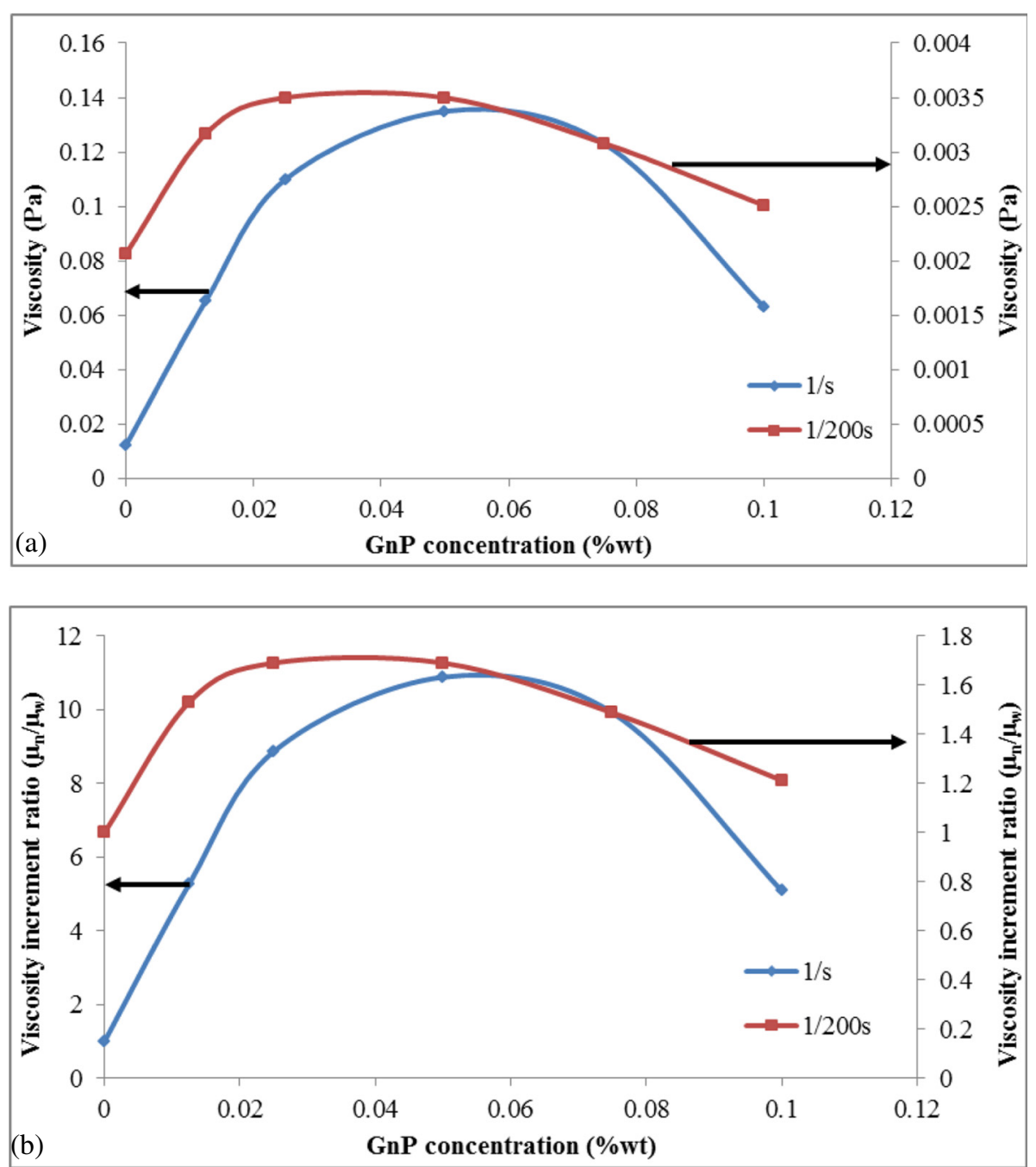

Figure 12 Plot of (a) viscosity and (b) viscosity increment ratio with respect to GO at varying GnP concentrations. GO concentration was fixed at $0.025 \mathrm{wt} \%$. 


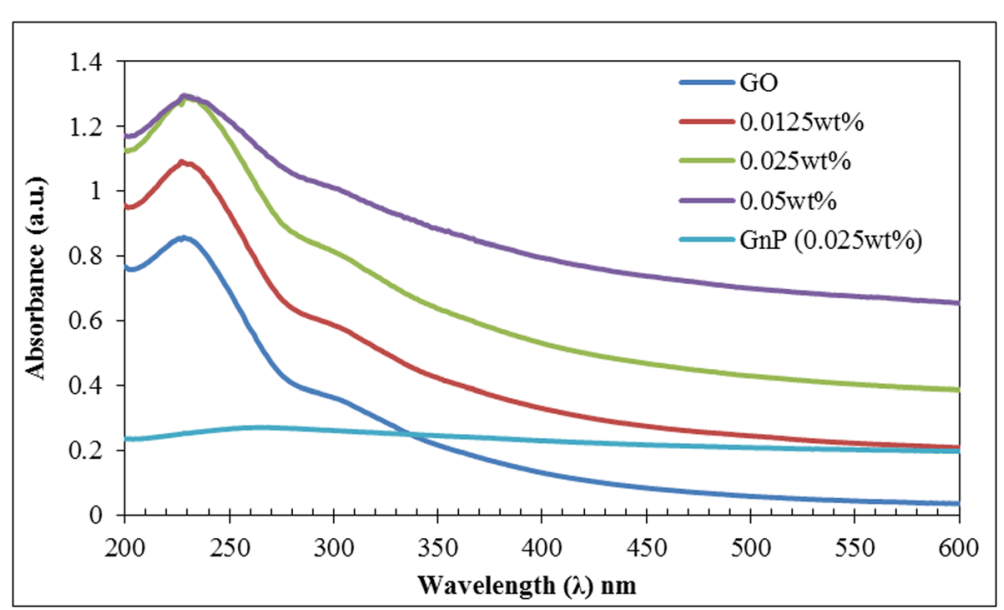

Figure 13 Plot of absorbance versus wavelength for GO-GnP at different loadings of GnP. GO concentration was fixed at 0.025 wt $\%$.

Figure 12a,b elaborates on the effect of increasing the amount of $\mathrm{GnP}$ on the overall viscosity measurement. It shows that increasing the GnP concentration results in the rise of viscosity at both low and high shear rates. The highest increment was recorded at two times the concentration of GO. This implies that the interaction between $\mathrm{GO}$ and $\mathrm{GnP}$ is the highest at this combination which also suggests that much of the hydrophilic sites on GO are occupied by GnP. Previous studies have also highlighted an optimum concentration range of colloidal mixtures to yield a stable hybrid system $[84,115,116]$. As the GnP concentration increases beyond this benchmark, the viscosity rapidly drops which may indicate the saturation of GnP on GO sheet and the remaining particles will strongly flocculate and form much bigger structures. This will alter the particle-particle and particle-fluid interaction within the colloidal mixture that would lead to the modification of the momentum transfer and eventual lowering of viscosity.

\section{Investigation of GO-GnP colloidal stability via particle absorbance measurement}

Figures 13 and 14 present the plot of light absorbance measurement on the colloidal solution at a specific range of wavelength which also gives an insight on the level of stability of the suspended particles. It was elucidated from Figure 13 that the addition of GnP into a GO-based solution increases the intensity of light absorbance which reflects a significant improvement on the stability of the system. Further, the rate of absorbency increment is much higher at low particle loading and gradually subsides with rising $\mathrm{GnP}$ concentration as shown in Figure 14. These findings are also in congruent to the previous approach on measuring particle

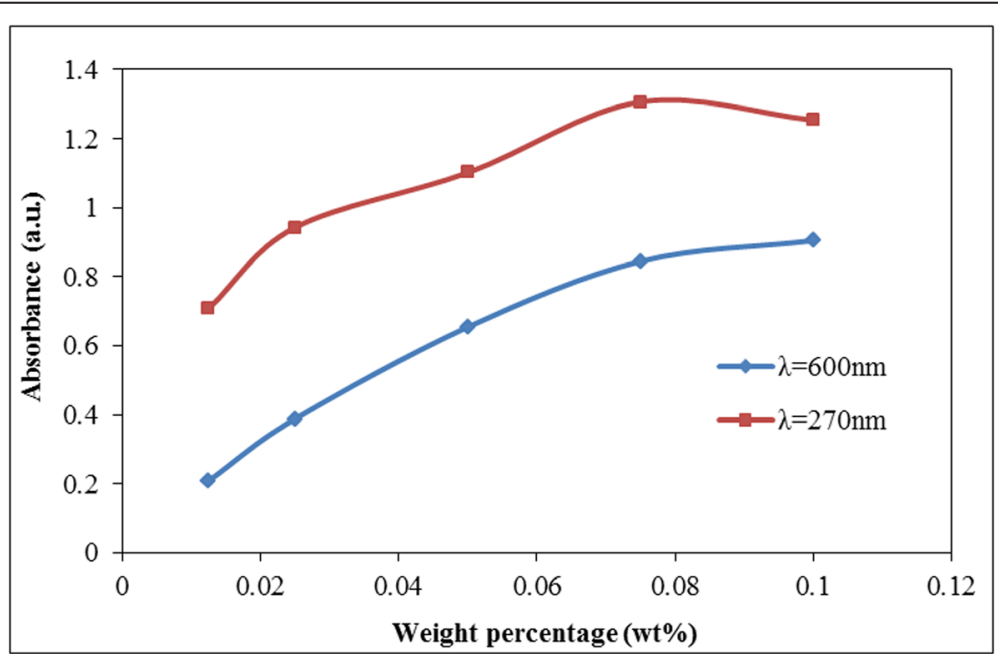

Figure 14 Plot of absorbance at different concentrations of GnP at a specific wavelength. GO concentration was fixed at 0.025 wt $\%$. 
light absorbance to determine the stability of weakly charged colloids in highly charged nanoparticles [107]. The results also vindicate the existence of optimum stabilizing window for the colloidal mixture to avoid flocculation and phase separation [84].

\section{Conclusion}

The present report highlighted for the first time the unique synergistic interaction between two different graphitic carbon structures, each having different charge strengths that enable a highly stable colloidal mixture to be accomplished. The results showed that GO, owing to its unique chemical and morphological structures, can be exploited as dispersant to effectively maintain GnP colloidal stability near its negligibly charged state (i.e., lowest charge density) where it was generally known to experience rapid aggregation due to extremely low repulsive forces. Series of measurements suggested that the interaction between the two colloids is mutually attractive in the long range but sufficiently repulsive in nature at a limited distance between the particles to prevent irreversible contact. Further, it was believed that the hovering of $\mathrm{GnP}$ particles on the planar and edges of charge-dominating GO structures prevents further contact between GnP particles. The imagery, electrophoresis, and rheological measurement techniques consolidate the existence of different physics to describe the stabilizing effect within the binary system. It is anticipated that this interesting behavior may provide favorable condition to further enhance the material property and expand the application frontier in science and technology.

\section{Abbreviations}

DI, deionized water; FT-IR, Fourier transform infrared; GnP, graphene nanoplatelets; GO, graphene oxide; T, temperature, K; TEM, transmission electron microscope; $\mathrm{UV}$, ultraviolet; XRD, X-ray diffraction.

\section{Greek}

wt $\%$, weight percentage; $\mu$, viscosity, $\mathrm{Pa}$

\section{Subscripts}

w, water; n, nanocolloids

\section{Competing interests}

The authors declare that they have no competing interests.

\section{Authors' contributions}

The manuscript was written through the contributions of all authors NZ, AB, SNK, HNM, MM, ES, MM, and NIS. All authors read and approved the final manuscript.

\section{Acknowledgements}

This research work has been supported by High Impact Research (MOHE-HIR) grant UM.C/625/1/HIR/MOHE/ENG/45 and IPPP grant PV113/2011A. The authors would like to thank members of Low Dimensional Materials Research Centre, Department of Physics and Colloid and Surface Science Lab, Department of
Chemistry, Faculty of Science, University of Malaya for the continuous support and assistance.

\section{Author details}

'Department of Mechanical Engineering, Faculty of Engineering, University of Malaya, Jalan Universiti, 50603 Kuala Lumpur, Malaysia. ${ }^{2}$ Low Dimensional Materials Research Centre (LDMRC), Department of Physics, Faculty of Science, University of Malaya, Jalan Universiti, 50603 Kuala Lumpur, Malaysia. ${ }^{3}$ Department of Chemistry, Faculty of Science, University of Malaya, Jalan Universiti, 50603 Kuala Lumpur, Malaysia. ${ }^{4}$ Department of Mechanical Engineering and Advanced Material Research Centre, University of Malaya, Jalan Universiti, 50603 Kuala Lumpur, Malaysia.

Received: 18 February 2015 Accepted: 26 March 2015

Published online: 08 May 2015

\section{References}

1. Muthoosamy K, Bai R, Manickam S. Graphene and graphene oxide as a docking station for modern drug delivery system. Curr Drug Deliv. 2014;11(6):701-18.

2. Novoselov KS, Fal V, Colombo L, Gellert P, Schwab M, Kim K. A roadmap for graphene. Nature. 2012;490(7419):192-200.

3. Stoller MD, Park S, Zhu Y, An J, Ruoff RS. Graphene-based ultracapacitors. Nano Lett. 2008;8(10):3498-502.

4. Balandin AA, Ghosh S, Bao W, Calizo I, Teweldebrhan D, Miao F, et al. Superior thermal conductivity of single-layer graphene. Nano Lett. 2008;8(3):902-7.

5. Novoselov K, Geim AK, Morozov S, Jiang D, Grigorieva MKI, Dubonos S, et al. Two-dimensional gas of massless Dirac fermions in graphene. Nature. 2005:438(7065):197-200.

6. Brodie BC. On the atomic weight of graphite. Philos Trans R Soc Lond. 1859;149:249-59.

7. Staudenmaier L. Method for the preparation of graphitic acid. Ber Dtsch Chem Ges. 1898;31:1481-7.

8. Hummers Jr WS, Offeman RE. Preparation of graphitic oxide. J Am Chem Soc. 1958;80(6):1339-9.

9. Stankovich S, Dikin DA, Piner RD, Kohlhaas KA, Kleinhammes A, Jia Y, et al. Synthesis of graphene-based nanosheets via chemical reduction of exfoliated graphite oxide. Carbon. 2007;45(7):1558-65.

10. Jiang $\mathrm{H}$. Chemical preparation of graphene-based nanomaterials and their applications in chemical and biological sensors. Small. 2011;7(17):2413-27.

11. Wang Y, Li Z, Wang J, Li J, Lin Y. Graphene and graphene oxide: biofunctionalization and applications in biotechnology. Trends Biotechnol. 2011;29(5):205-12.

12. Wang L, Lee K, Sun Y-Y, Lucking M, Chen Z, Zhao JJ, et al. Graphene oxide as an ideal substrate for hydrogen storage. ACS Nano. 2009;3(10):2995-3000.

13. Erickson K, Erni R, Lee Z, Alem N, Gannett W, Zettl A. Determination of the local chemical structure of graphene oxide and reduced graphene oxide. Adv Mater. 2010;22(40):4467-72.

14. Dreyer DR, Park S, Bielawski CW, Ruoff RS. The chemistry of graphene oxide. Chem Soc Rev. 2010;39(1):228-40.

15. Szabó T, Berkesi O, Forgó P, Josepovits K, Sanakis Y, Petridis D, et al. Evolution of surface functional groups in a series of progressively oxidized graphite oxides. Chem Mater. 2006;18(11):2740-9.

16. Cote LJ, Kim J, Tung VC, Luo J, Kim F, Huang J. Graphene oxide as surfactant sheets. Pure Appl Chem. 2010;83(1):95-110.

17. Luo J, Cote LJ, Tung VC, Tan AT, Goins PE, Wu J, et al. Graphene oxide nanocolloids. J Am Chem Soc. 2010;132(50):17667-9.

18. Kim J, Cote LJ, Kim F, Yuan W, Shull KR, Huang J. Graphene oxide sheets at interfaces. J Am Chem Soc. 2010;132(23):8180-6.

19. Aboutalebi SH, Chidembo AT, Salari M, Konstantinov K, Wexler D, Liu HK, et al. Comparison of GO, GO/MWCNTs composite and MWCNTs as potential electrode materials for supercapacitors. Energy Environ Sci. 2011;4(5):1855-65.

20. Han P, Yue Y, Liu Z, Xu W, Zhang L, Xu H, et al. Graphene oxide nanosheets/multi-walled carbon nanotubes hybrid as an excellent electrocatalytic material towards VO 2+NO 2+ redox couples for vanadium redox flow batteries. Energy Environ Sci. 2011;4(11):4710-7.

21. Kim J, Tung VC, Huang J. Water processable graphene oxide: single walled carbon nanotube composite as anode modifier for polymer solar cells. Adv Energy Mater. 2011;1(6):1052-7.

22. Kim Y-K, Min D-H. Preparation of scrolled graphene oxides with multi-walled carbon nanotube templates. Carbon. 2010;48(15):4283-8. 
23. Luo S, Wu Y, Gou H. A voltammetric sensor based on GO-MWNTs hybrid nanomaterial-modified electrode for determination of carbendazim in soil and water samples. Ionics. 2013;19(4):673-80

24. Mani V, Chen S-M, Lou B-S. Three dimensional graphene oxide-carbon nanotubes and graphene-carbon nanotubes hybrids. Int J Electrochem Sci. 2013;8:11641-60

25. Qiu L, Yang X, Gou X, Yang W, Ma ZF, Wallace GG, et al. Dispersing carbon nanotubes with graphene oxide in water and synergistic effects between graphene derivatives. Chem A Eur J. 2010;16(35):10653-8.

26. Zhang C, Ren L, Wang X, Liu T. Graphene oxide-assisted dispersion of pristine multiwalled carbon nanotubes in aqueous media. J Physical Chem C. 2010;114(26):11435-40.

27. Sanchez VC, Jachak A, Hurt RH, Kane AB. Biological interactions of graphene-family nanomaterials: an interdisciplinary review. Chem Res Toxicol. 2011;25(1):15-34.

28. Tung VC, Huang J-H, Tevis I, Kim F, Kim J, Chu C-W, et al. Surfactant-free water-processable photoconductive all-carbon composite. J Am Chem Soc. 2011;133(13):4940-7.

29. Kim KH, Yang M, Cho KM, Jun Y-S, Lee SB, Jung H-T. High quality reduced graphene oxide through repairing with multi-layered graphene ball nanostructures. Sci Rep. 2013;3:3251

30. Mani V, Devadas B, Chen S-M. Direct electrochemistry of glucose oxidase at electrochemically reduced graphene oxide-multiwalled carbon nanotubes hybrid material modified electrode for glucose biosensor. Biosens Bioelectron. 2013;41:309-15.

31. Tung VC, Huang J-H, Kim J, Smith AJ, Chu C-W, Huang J. Towards solution processed all-carbon solar cells: a perspective. Energy. Environ Sci. 2012;5(7):7810-8

32. Vaisman L, Wagner HD, Marom G. The role of surfactants in dispersion of carbon nanotubes. Adv Colloid Interface Sci. 2006;128:37-46.

33. Zheng M, Jagota A, Semke ED, Diner BA, McLean RS, Lustig SR, et al. DNA-assisted dispersion and separation of carbon nanotubes. Nat Mater 2003;2(5):338-42

34. Hsiao A-E, Tsai S-Y, Hsu M-W, Chang S-J. Decoration of multi-walled carbon nanotubes by polymer wrapping and its application in MWCNT/polyethylene composites. Nanoscale Res Lett. 2012:7(1):1-5.

35. Gurunathan S, Han JW, Eppakayala V, Dayem AA, Kwon D-N, Kim J-H. Biocompatibility effects of biologically synthesized graphene in primary mouse embryonic fibroblast cells. Nanoscale Res Lett. 2013;8(1):1-13.

36. Han D, Meng Z, Wu D, Zhang C, Zhu H. Thermal properties of carbon black aqueous nanofluids for solar absorption. Nanoscale Res Lett. 2011;6(1):1-7.

37. Liu M, Lin MC, Wang C. Enhancements of thermal conductivities with Cu, $\mathrm{CuO}$, and carbon nanotube nanofluids and application of MWNT/water nanofluid on a water chiller system. Nanoscale Res Lett. 2011;6(1):1-13.

38. Ruan B, Jacobi AM. Ultrasonication effects on thermal and rheological properties of carbon nanotube suspensions. Nanoscale Res Lett. 2012;7(1):1-14.

39. Wang F, Han L, Zhang Z, Fang X, Shi J, Ma W. Surfactant-free ionic liquid-based nanofluids with remarkable thermal conductivity enhancement at very low loading of graphene. Nanoscale Res Lett. 2012;7(1):1-7.

40. Xie H, Yu W, Li Y, Chen L. Discussion on the thermal conductivity enhancement of nanofluids. Nanoscale Res Lett. 2011;6(1):124

41. Zhao W, Song C, Pehrsson PE. Water-soluble and optically pH-sensitive single-walled carbon nanotubes from surface modification. J Am Chem Soc. 2002;124(42):12418-9.

42. Mickelson E, Chiang I, Zimmerman J, Boul P, Lozano J, Liu J, et al. Solvation of fluorinated single-wall carbon nanotubes in alcohol solvents. J Phys Chem B. 1999;103(21):4318-22.

43. Chen J, Hamon MA, Hu H, Chen Y, Rao AM, Eklund PC, et al. Solution properties of single-walled carbon nanotubes. Science. 1998;282(5386):95-8.

44. Baby TT, Ramaprabhu S. Enhanced convective heat transfer using graphene dispersed nanofluids. Nanoscale Res Lett. 2011;6(1):1-9.

45. Balasubramanian K, Burghard M. Chemically functionalized carbon nanotubes. Small. 2005;1(2):180-92.

46. Mu X, Wu X, Zhang T, Go DB, Luo T. Thermal transport in graphene oxide-from ballistic extreme to amorphous limit. Sci Rep. 2014;4:3909.

47. Moore VC, Strano MS, Haroz EH, Hauge RH, Smalley RE, Schmidt J, et al. Individually suspended single-walled carbon nanotubes in various surfactants. Nano Lett. 2003:3(10):1379-82

48. Chen RJ, Bangsaruntip S, Drouvalakis KA, Kam NWS, Shim M, Li Y, et al. Noncovalent functionalization of carbon nanotubes for highly specific electronic biosensors. Proc Natl Acad Sci. 2003;100(9):4984-9.
49. Sadri R, Ahmadi G, Togun H, Dahari M, Kazi SN, Sadeghinezhad E, et al. An experimental study on thermal conductivity and viscosity of nanofluids containing carbon nanotubes. Nanoscale Res Lett. 2014;9(1):151.

50. Zhang W, Zhang Z, Zhang Y. The application of carbon nanotubes in target drug delivery systems for cancer therapies. Nanoscale Res Lett. 2011;6(1):1-22.

51. Wolf E. Practical Productions of Graphene, Supply and Cost, in Applications of Graphene. Springer; 2014. p. 19-38.

52. Lu J, Do I, Fukushima H, Lee I, Drzal LT. Stable aqueous suspension and self-assembly of graphite nanoplatelets coated with various polyelectrolytes. J Nanomaterials. 2010;2010:2.

53. Drzal LT, Fukushima H. Expanded graphite and products produced therefrom. 2004. US Patent 20,040,127,621.

54. Lee $S, C h o D$, Drzal L. Real-time observation of the expansion behavior of intercalated graphite flake. J Mater Sci. 2005;40(1):231-4.

55. Jeon J, Jeong S-G, Lee J-H, Seo J, Kim S. High thermal performance composite PCMs loading XGnP for application to building using radiant floor heating system. Solar Energy Mater Solar Cells. 2012;101:51-6.

56. Drzal L, Fukushima H. Expanded graphite and products produced therefrom. 2003. Google Patents.

57. Fukushima H. Graphite nanoreinforcements in polymer nanocomposites. 2003.

58. Kavan L, Yum JH, Grätzel M. Optically transparent cathode for dye-sensitized solar cells based on graphene nanoplatelets. ACS Nano. 2010;5(1):165-72.

59. Drzal LT, Fukushima $H$. Exfoliated graphite nanoplatelets ( $\mathrm{XGnP}$ ): A carbon nanotube alternative. Proceedings of NSTI Nanotechnology Coneference and Trade Show, 2006.

60. Chung D. Exfoliation of graphite. J Mater Sci. 1987;22(12):4190-8.

61. Kalaitzidou K, Fukushima H, Drzal LT. Multifunctional polypropylene composites produced by incorporation of exfoliated graphite nanoplatelets. Carbon. 2007:45(7):1446-52

62. Biswas S, Fukushima H, Drzal LT. Mechanical and electrical property enhancement in exfoliated graphene nanoplatelet/liquid crystalline polymer nanocomposites. Composites Part A: Applied Sci Manufact. 2011;42(4):371-5.

63. Mehrali M, Sadeghinezhad E, Latibari ST, Kazi SN, Mehrali M, Zubir MNBM, et al. Investigation of thermal conductivity and rheological properties of nanofluids containing graphene nanoplatelets. Nanoscale Res Lett. 2014:9(1):1-12

64. Hwang S-H, Park HW, Park Y-B. Piezoresistive behavior and multi-directional strain sensing ability of carbon nanotube-graphene nanoplatelet hybrid sheets. Smart Materials Structures. 2013;22(1):015013.

65. Xiang J, Drzal LT. Thermal conductivity of exfoliated graphite nanoplatelet paper. Carbon. 2011:49(3):773-8.

66. xGnP Technical Data Sheet. DOI: http://xgsciences.com/wp-content/ uploads/2012/10/10-15-13_xGnP-C_Data-Sheet.pdf.

67. Roghani-Mamaqani H, Haddadi-AsI V, Khezri K, Salami-Kalajahi M. Polystyrene grafted graphene nanoplatelets with various graft densities by atom transfer radical polymerization from the edge carboxyl groups. RSC Advances. 2014.

68. Leng Y, Gu J, Cao W, Zhang T-Y. Influences of density and flake size on the mechanical properties of flexible graphite. Carbon. 1998;36(7):875-81.

69. Fukushima $H$, Drzal L, Rook B, Rich M. Thermal conductivity of exfoliated graphite nanocomposites. J Thermal Analysis Calorimetry. 2006;85(1):235-8.

70. Xiang J, Drzal LT. Investigation of exfoliated graphite nanoplatelets $(<\mathrm{i}\rangle$ $x</ i>G n P)$ in improving thermal conductivity of paraffin wax-based phase change material. Solar Energy Mater Solar Cells. 2011;95(7):1811-8.

71. Fukushima H, Drzal LT. Nylon-exfoliated graphite nanoplatelet (xGnP) nanocomposites with enhanced mechanical, electrical and thermal properties. in NSTI Nanotech. 2006.

72. Kalaitzidou K, Fukushima H, Drzal L. Multifunctional nanocomposites made of polypropylene reinforced with exfoliated graphite Nanoplatelets (xGnP). 2006.

73. Hendricks TR, Lu J, Drzal LT, Lee I. Intact pattern transfer of conductive exfoliated graphite nanoplatelet composite films to polyelectrolyte multilayer platforms. Adv Mater. 2008;20(10):2008-12

74. Lu J, Drzal LT, Worden RM, Lee I. Simple fabrication of a highly sensitive glucose biosensor using enzymes immobilized in exfoliated graphite nanoplatelets nafion membrane. Chem Mater. 2007;19(25):6240-6.

75. Park H-M, Kalaitzidou K, Fukushima H, Drzal LT. Exfoliated graphite nanoplatelet (xGnP)/polypropylene nanocomposites. Michigan State University, Composite Materials \& Structures Center; 2007.

76. Kim S, Drzal LT. Comparison of exfoliated graphite nanoplatelets ( $\mathrm{XGnP}$ ) and CNTs for reinforcement of EVA nanocomposites fabricated by solution compounding method and three screw rotating systems. J Adhesion Sci Technol. 2009;23(12):1623-38. 
77. Do I-H. Metal Decoration of exfoliated graphite nanoplatelets ( $x G n P)$ for fuel cell applications, Ph.D. Dissertation; Michigan State University, 2006, East Lansing, Michigan.

78. Aria Al, Gharib M. Reversible tuning of the wettability of carbon nanotube arrays: the effect of ultraviolet/ozone and vacuum pyrolysis treatments. Langmuir. 2011;27(14):9005-11.

79. Biswas S, Drzal LT. A novel approach to create a highly ordered monolayer film of graphene nanosheets at the liquid - liquid interface. Nano Lett. 2008;9(1):167-72

80. ASTM D4187-82, Methods of test for zeta potential of colloids in water and waste water (Withdrawn 1990), ASTM International, West Conshohocken, PA, www.astm.org.

81. Si Y, Samulski ET. Synthesis of water soluble graphene. Nano Lett. 2008;8(6):1679-82

82. Mani V, Vilian AE, Chen S-M. Graphene oxide dispersed carbon nanotube and iron phthalocyanine composite modified electrode for the electrocatalytic determination of hydrazine. Int J Electrochem Sci. 2012;7:12774-85.

83. Zhang LL, Xiong Z, Zhao X. Pillaring chemically exfoliated graphene oxide with carbon nanotubes for photocatalytic degradation of dyes under visible light irradiation. ACS Nano. 2010;4(11):7030-6.

84. Tohver V, Chan A, Sakurada O, Lewis JA. Nanoparticle engineering of complex fluid behavior. Langmuir. 2001;17(26):8414-21.

85. Tohver V, Smay JE, Braem A, Braun PV, Lewis JA. Nanoparticle halos: a new colloid stabilization mechanism. Proc Natl Acad Sci. 2001;98(16):8950-4.

86. Marcano DC, Kosynkin DV, Berlin JM, Sinitskii A, Sun Z, Slesarev A, et al, Improved synthesis of graphene oxide. ACS Nano. 2010;4(8):4806-14.

87. Huang NM, Lim H, Chia C, Yarmo M, Muhamad M. Simple roomtemperature preparation of high-yield large-area graphene oxide. Int J Nanomedicine. 2011;6:3443.

88. Lim HN, Huang NM, Lim S, Harrison I, Chia C. Fabrication and characterization of graphene hydrogel via hydrothermal approach as a scaffold for preliminary study of cell growth. Int J Nanomedicine. 2011;6:1817.

89. Novoselov KS, Geim AK, Morozov S, Jiang D, Zhang Y, Dubonos S, et al. Electric field effect in atomically thin carbon films. Science. 2004;306(5696):666-9.

90. Lu X, Yu M, Huang H, Ruoff RS. Tailoring graphite with the goal of achieving single sheets. Nanotechnology. 1999;10(3):269.

91. Kopelevich Y, Esquinazi P. Graphene physics in graphite. Adv Mater. 2007:19(24):4559-63.

92. Park S, An J, Jung I, Piner RD, An SJ, Li X, et al. Colloidal suspensions of highly reduced graphene oxide in a wide variety of organic solvents. Nano Lett. 2009;9(4):1593-7.

93. Dikin DA, Stankovich S, Zimney EJ, Piner RD, Dommett GH, Evmenenko G, et al. Preparation and characterization of graphene oxide paper. Nature. 2007;448(7152):457-60.

94. Characterization of $\mathrm{xGnP} \otimes$ Grade C Materials [cited 201431 September]. DOl: http://xgsciences.com/wp-content/uploads/2012/10/Characterizationof-Grade-C-xGnP-04-30-2012-2.pdf

95. Acik M, Lee G, Mattevi C, Chhowalla M, Cho K, Chabal Y. Unusual infrared-absorption mechanism in thermally reduced graphene oxide. Nat Mater. 2010;9(10):840-5.

96. Li D, Müller MB, Gilje S, Kaner RB, Wallace GG. Processable aqueous dispersions of graphene nanosheets. Nat Nanotechnol. 2008;3(2):101-5.

97. Sadeghinezhad E, Mehrali M, Tahan Latibari S, Mehrali M, Kazi S, Oon CS, et al. Experimental investigation of convective heat transfer using graphene nanoplatelet based nanofluids under turbulent flow conditions. Ind Eng Chem Res. 2014;53(31):12455-65.

98. Yang D, Velamakanni A, Bozoklu G, Park S, Stoller M, Piner RD, et al. Chemical analysis of graphene oxide films after heat and chemical treatments by X-ray photoelectron and Micro-Raman spectroscopy. Carbon. 2009;47(1):145-52.

99. Tuinstra F, Koenig JL. Raman spectrum of graphite. J Chem Phys. 1970;53(3):1126-30.

100. Kudin KN, Ozbas B, Schniepp HC, Prud'Homme RK, Aksay IA, Car R. Raman spectra of graphite oxide and functionalized graphene sheets. Nano Lett. 2008;8(1):36-41.

101. Mehrali M, Latibari ST, Mehrali M, Metselaar HSC, Silakhori M. Shape-stabilized phase change materials with high thermal conductivity based on paraffin/ graphene oxide composite. Energy Conversion Manag. 2013;67:275-82.

102. Cheng M, Yang R, Zhang L, Shi Z, Yang W, Wang D, et al. Restoration of graphene from graphene oxide by defect repair. Carbon. 2012;50(7):2581-7.

103. Wang $H$, Robinson JT, Li X, Dai H. Solvothermal reduction of chemically exfoliated graphene sheets. J Am Chem Soc. 2009;131(29):9910-1.
104. Pei S, Zhao J, Du J, Ren W, Cheng H-M. Direct reduction of graphene oxide films into highly conductive and flexible graphene films by hydrohalic acids. Carbon. 2010;48(15):4466-74.

105. Kaszuba M, Corbett J, Watson FM, Jones A. High-concentration zeta potential measurements using light-scattering techniques. Philos TransA Math Phys. Eng Sci. 2010;368(1927):4439-51.

106. Ji S, Herman D, Walz JY. Manipulating microparticle interactions using highly charged nanoparticles. Colloids Surf A Physicochem Eng Asp. 2012;396:51-62.

107. Herman D, Walz JY. Stabilization of weakly charged microparticles using highly charged nanoparticles. Langmuir. 2013;29(20):5982-94.

108. Kong D, Yang H, Yang Y, Wei S, Wang J, Cheng B. Dispersion behavior and stabilization mechanism of alumina powders in silica sol. Mater Lett. 2004;58(27):3503-8.

109. Zhu J, Yudasaka M, Zhang M, lijima S. Dispersing carbon nanotubes in water: a noncovalent and nonorganic way. J Phys Chem B. 2004;108(31):11317-20

110. Xing X, Sun G, Li Z, Ngai T. Stabilization of colloidal suspensions: competing effects of nanoparticle halos and depletion mechanism. Langmuir. 2012;28(46):16022-8

111. McKee CT, Walz JY. Interaction forces between colloidal particles in a solution of like-charged, adsorbing nanoparticles. J Colloid Interface Sci. 2012;365(1):72-80

112. Chan AT. Size ratio effects on interparticle interactions and phase behavior of microsphere - nanoparticle mixtures. Langmuir. 2008;24(20):11399-405.

113. Verwey EJW, Overbeek JTG. Theory of the stability of lyophobic colloids. Amsterdam: Elsevier; 1948.

114. Chan AT, Lewis JA. Electrostatically tuned interactions in silica microspherepolystyrene nanoparticle mixtures. Langmuir. 2005;21(19):8576-9.

115. Huang H, Ruckenstein E. Decoration of microparticles by highly charged nanoparticles. J Phys Chem B. 2013;117(20):6318-22.

116. Karimian $\mathrm{H}$, Babaluo A. Halos mechanism in stabilizing of colloidal suspensions: nanoparticle weight fraction and pH effects. J Eur Ceramic Soc. 2007;27(1):19-25.

\section{Submit your manuscript to a SpringerOpen ${ }^{\odot}$ journal and benefit from:}

- Convenient online submission

- Rigorous peer review

- Immediate publication on acceptance

- Open access: articles freely available online

- High visibility within the field

- Retaining the copyright to your article

Submit your next manuscript at $>$ springeropen.com 